\title{
ARQUITECTURA, CIUDAD Y TERRITORIO A FINALES DE LA ILUSTRACIÓN
}

\author{
Architecture, City and Territory \\ at the End of Enlightenment
}

\section{Carlos SAMBRICIO}

Escuela Técnica Superior de Arquitectura de Madrid. UPM

csambricio@hotmail.com

RESUMEN: Frente a quienes identifican el origen de la «arquitectura de la Ilustración" con la influencia que pudo tener el clasicismo romano, en los primeros momentos de la segunda mitad del XVIII, quizá conviniera precisar que entre la crítica al barroco y la adopción de tales modelos transcurrieron más de treinta años. Dicho de otro modo, frente a quienes entiendan y afronten la historia de la arquitectura o del urbanismo como sucesión de estilos cabe señalar como el paso de un planteamiento a otro no fue brusco, coexistiendo y solapándose antiguos supuestos con la génesis de nuevos planteamientos.

Palabras clave: Arquitectura; urbanismo; territorio; división administrativa; clasicismo; ciudad liberal.

ABSTRACT: Unlike those who identify the beginning of «Enlightenment Architecture» with the influence that Roman Classicism could have had at the advent of the second half of the Eighteenth Century, perhaps it is worth clarifying that between the critique of the Baroque and the adoption of such models lies a period of more than thirty years. In other words, unlike those who understand and confront the history of architecture or urban planning as a succession of styles it might be worth considering how the switch from one type of approach to another was not sudden but that previous suppositions coexisted and overlapped with the genesis of new ways of planning.

Key words: Architecture; Urbanism; Territory; Administrative Division; Classicism; Liberal City. 
Frente a quienes identifican el origen de la «arquitectura de la Ilustración» con la influencia que pudo tener el clasicismo romano, en los primeros momentos de la segunda mitad del XVIII, quizá conviniera precisar que entre la crítica al barroco y la adopción de tales modelos transcurrieron más de treinta años. Dicho de otro modo, frente a quienes entiendan y afronten la historia de la arquitectura o del urbanismo como sucesión de estilos cabe señalar como el paso de un planteamiento a otro no fue brusco, coexistiendo y solapándose antiguos supuestos con la génesis de nuevos planteamientos. Y si dicha génesis precisa ser entendida, importa por lo mismo conocer cuál fue su genealogía. Las contradicciones se presentan como reflejo de tensiones epistemológicas siendo preciso conocer, comprender y valorar las mismas. Sustituyamos pues la historia de los estilos, bien por una historia de las ideas, bien por una historia de las contradicciones. Hubo quien, en la Alemania de Weimar, fue definido como chiffonier de la culture reconociendo en él a quien era capaz de ignorar el erudito conjunto de datos para entresacar, de ellos, su significado. Releamos a Kracauer y pensemos sobre la ciudad en los finales de la Ilustración.

En el primer cuarto del XVIII, la reacción antibarroca impuso definir «reglas» y debatir sobre el «buen gusto", depurando "aberraciones» anteriores: y en la preocupación por entender que debían ser las «reglas» Luzán dedicaría uno de los capítulos de su Poética (aquel qué hacía referencia al «Origen, progresos y esencia de la poesía") a explicar cómo la poética referencia "a la choza" debía valorarse como punto de partida ${ }^{1}$. Censurar la corrupción en la poética implicaba reconocer la existencia de un momento anterior, en el que se aceptaron "reglas»: y frente a la preocupación archivística que en su día mostró Ambrosio de Morales -buscando localizar documentos-, el levantamiento de monumentos se convirtió, en torno a 1750 , no solo en testimonio de lo existente, sino en reflejo de la preocupación de quienes buscaban conocer las reglas merced a las cuales se construyeron, en el pasado, aquellos monumentos. La historia de la arquitectura no sería entonces historia de formas (de estilos) sino historia de problemas, dudas, contradicciones y soluciones. Así, y frente a los taccuini renacentistas, a los esbozos a vuelapluma, la preocupación existente en el XVIII por la fidelidad en el dibujo de las ruinas fue determinante, entendiéndose el levantamiento como modo de representación científico frente al impreciso, cuando no "históricamente falso", dibujo a mano alzada. Y cuando Preciado de la Vega reclamó -al poco de haber creado Aróstegui en Roma la Academia de España- comprar estampas (grabados) para los estudios de arquitectura, implícitamente reconocía la necesidad de asumir el debate abierto en Paris sobre la imitación.

Si el arte precisaba de reglas, acatar estas era la condición necesaria para alcanzar el buen gusto. Así Diderot y D'Alambert abrieron el debate sobre si la arquitectura era o no un arte que imita la naturaleza, idea recogida en España por

1. LuZÁn, Ignacio. Poética o reglas de la poesía en general y de sus principales especies. Madrid, 1789. En la segunda edición (I, IV) introducía una reflexión sobre la idea de que la poesía (literatura) era universal, quedando en consecuencia por encima de las diferencias idiomáticas. 
Luzán al reclamar -en 1752- la necesidad de imitar... «la naturaleza en lo universal o en lo particular» ${ }^{2}$. "Imitar» era el resultado de copiar un modelo antiguo valorado por la tradición. No solo implicaba asimilar la experiencia de los maestros, sino que imponía ajustarse a convenciones y características, opinión confirmada por un Moratín quien -citando a Quintiliano- destacaría que «imitación es el resultado activo de la lectura reiterada ${ }^{3}$. Ante la carencia de una sólida tratadística española en temas de arquitectura se hizo preciso -como hicieran José de Castañeda o Diego de Villanueva al reclamar el estudio de los órdenes clásicos- recurrir a los textos de Perrault o Blondel. El interés por la antigüedad clásica llevó a Aróstegui a reivindicar -en la "Oración» pronunciada en 1752 en la Academia de San Fernando- su estudio como base de una nueva arquitectura. Justificaba la misma al señalar cómo el clasicismo... «dio a España el famoso Templo de Hércules en Cádiz; los celebrados teatros de Sagunto, Itálica y Tarragona; los acueductos y puentes de Segovia, Mérida, Almaraz y Alcántara, nobles vestigios de la grandeza romana. Así se levantaron después los célebres templos de Sevilla, Toledo, Córdoba, León, Burgos y Salamanca. Y así se pasmó el Mundo al ver la octava maravilla del Real Palacio y Monasterio de El Escorial» ${ }^{4}$. Su comentario influiría no solo entre quienes habían asumido la tarea de "localizar monumentos" (los testimonios del pasado) sino que, al primar determinados testimonios del pasado frente a otros, mostraba su sintonía con la opinión formulada en Francia por el abate Dubos (... «no todo lo que se ha hecho merece ser descrito") al aconsejar un estudio selectivo de la antigüedad. Y que tal opinión fue pronto asumida por la Academia de San Fernando es evidente al estudiar los temas propuestos por esta tanto en sus «Premios Generales» como en sus "Ayudas de Costas".

En torno a 1780 la situación comenzaba a cambiar al entender la Academia de San Fernando (sede en aquellos momentos del saber teórico) que limitar el interés

2. Berbel Rodríguez, José J. Orígenes de la tragedia neoclásica (1737-1754): la Academia del Buen Gusto. Sevilla: Universidad Sevilla, Secretariado de Publicaciones, 2003, n. 20.

3. Moratín escribió sobre invención e imitación: «Lo que se llama inventar en las artes no es otra cosa que imitar lo que existe en la naturaleza, o en las obras de los hombres, que la imitaron ya. El que se proponga no coincidir nunca en lo mismo que otros hicieron, se propone un método equivocado y absurdo, y el que huye de acomodar en sus obras las perfecciones de otro artífice, pudiendo hacerlo con oportunidad, voluntariamente yerra [...]. El que no estudia por buenos principios la razón de las artes, nada de esto entiende; y luego que halla en cualquier obra algún pasaje que tenga semejanza con otro, eso le basta para llamar plagio, copia, robo execrable, lo que es tal vez prueba de talento, con profunda meditación». Ver la edición de LÁzARO CARRETER, Fernando. Introducción. Moratín en su teatro. Labor: Barcelona: 1970, t. 1, p. 232.

4. Real Academia de Bellas Artes de San Fernando. Distribución de los Premios concedidos por el Rey Nuestro Señor. Madrid, 1752, p. 39.

5. Arbaiza Blanco-Soler, Silvia. "Los dibujos de Arquitectura en la Real Academia de Bellas Artes de San Fernando (Madrid)». arq.urb, 2013 (primer semestre), 9, pp. 98-113, así como los siete trabajos publicados por la misma, junto con HERAS CASAS, Carmen. "Inventario de los dibujos arquitectónicos (de los siglos XVIII y XIX) en el Museo de la Real Academia de Bellas Artes de San Fernando». Academia (Real Academia de Bellas Artes de San Fernando) entre 2001 y 2007. 
por la arquitectura del pasado al estudio de la regla conllevaba tanto no cuestionar el origen de la arquitectura como ignorar los valores de la arquitectura local. Si poco antes Cadalso había formulado, en sus Noches lúgubres, la referencia a la ruina de la que partiría el estudio de los monumentos del pasado, en 1779 Antonio Capmany reclamaba, en el primer tomo de su Historia del comercio y las artes de la antigua Barcelona, la grandeza de la arquitectura gótica, introduciendo un singular quiebro en la hasta entonces mecánica identificación del término «antigüedades arquitectónicas" con el de "ruinas». Si las primeras habían sido paradigma del hacer arquitectónico, a partir de 1780 el interés por las ruinas daría pie a una historia razonada, basada tanto en estudiar los orígenes de la arquitectura como en valorar los cambios que este había experimentado en su solución. En torno a 1750 el interés de los eruditos había sido el levantamiento de los monumentos antiguos con objeto de conocer las reglas que habían determinado su composición, a partir de 1780 se buscó la clasificación de los monumentos cerrando así el ciclo abierto en torno a 1730 por quienes buscaban hacer ver... «cuán deformes monstruos puede concebir una fantasía desordenada ${ }^{6}$.

Entre 1780 y 1830 -entre los primeros comentarios de Capmany sobre la arquitectura gótica catalana, la reivindicación de las ruinas que formulara Cadalso y la primera formulación de una "historia de la arquitectura»- pasaron algo más de cincuenta años, lapso en el que se configuró la reivindicación de una arquitectura local, se reivindicó la posibilidad de contrastar el gótico con el dórico o se cuestionaron los conceptos de imitación o invención. Cierto que el estudio de las ruinas llevó -como esbozara Bosarte y al poco reclamara Jovellanos- a reivindicar una arquitectura gótica que dejaba de entenderse como «manera bárbara». Pero hubo más: porque de la misma manera que se cuestionaba el cómo afrontar la arquitectura del pasado cambió el concepto de ciudad.

Por una parte, si hasta el momento la única preocupación de quienes acometieron el trazado de ciudades fue introducir reformas y cambios en los núcleos existentes, en torno a la fecha citada se cuestionaría el devoir d'embellir que había caracterizado los primeros años de la Ilustración al trastocarse la imagen de los núcleos urbanos (imagen ligada a la historia, de manera que, como se señalara en "Sinapia"... "quien ha visto una, las ha visto todas») ${ }^{7}$. Paralelamente, al definirse los núcleos urbanos no solo como lugares de residencia, sino también como espacios para la producción de riqueza, la definición de programas de necesidades específicos (las necesidades de la ciudad-lazareto no eran las mismas que las de una ciudad-arsenal, por lo mismo que la ciudad-fábrica nada tenía ya en común con la

6. Sebold, Russell P. «Martin Sarmiento y la doctrina neoclásica». Ínsula, 1977, 366, pp. 1-12.

7. SAmbricio, Carlos. "Sinapia: utopía, territorio y ciudad a finales del siglo XVIII". Scripta Nova. Revista Electrónica de Geografía y Ciencias Sociales. [En línea]. Barcelona: Universidad de Barcelona, 1 de mayo de 2014, vol. XVIII, n. ${ }^{\circ} 475$. ISSN: 1138-9788. http://www.ub.es/geocrit/sn/sn-475.htm. Consultado septiembre 2015 . 
ciudad-colonizadora) determinó no solo afrontar el trazado de la población desde parámetros distintos, sino también cambiar la escala de intervención, proponiéndose en consecuencia la creación de nuevos espacios económicos o, lo que es lo mismo, la ordenación económica del territorio.

Si las ciencias (las matemáticas) habían sido determinantes tanto en la formación de los primeros novatores como en la Encyclopédie de Diderot y D'Alambert, la economía política fue la referencia en torno a la cual gravitaron -en las últimas décadas del XVIII y principios del XIX- los distintos saberes. Uztarroz, Walls, Campomanes y una larga serie de pensadores económicos (a los que cabría añadir Cantillon, Forbonnais, Mably, Du Quesnay...) tuvieron un papel más que determinante, como lo prueban, por ejemplo, tanto el testimonio que un criollo como Belgrano diera, tras sus años de estudio en España, detallando sus preocupaciones y lecturas, como los comentarios que Jovellanos hiciera a su amigo Hardins sobre lo frecuente que resultaba encontrar, en aquella España, jóvenes cuya única lectura era el Code de Mably.

Desde la economía política tomó cuerpo la voluntad por supeditar el trazado de determinados núcleos urbanos a programas económicos precisos, de manera tal que cada ciudad se entendiera como "ciudades servicio", proponiéndose respuestas específicas a la función (actividad económica) que la población debía desarrollar?. Aparecieron ciudades-fábricas (Brihuega o Vigo, por ejemplo) diferentes de las ciudades-lazareto (Mahón), ciudades-arsenal (Ferrol, San Carlos o Cartagena), ciudades-colonizadoras (La Carolina, Palma del Rio, Las Navas de Tolosa...), ciudades-canal (Monte Torrero, en el Canal Imperial) o ciudades-cuartel (Nueva Tabarca o la ciudad militar para 100.000 personas propuesta en Alcalá de Henares). Cada una se concibió y trazó desde un programa de necesidades específico que determinó tamaño y trazado, características de sus equipamientos y tipos de viviendas de quienes debían habitarlas. Pero hubo más: frente a actuaciones puntuales se planteó la creación de espacios económicos («intendencias", como se denominaron primero en Sierra Morena y Nueva Andalucía y luego en América, potenciadas por los «visitadores»), lo que supuso cuestionar la ancestral división administrativa del territorio. En este sentido, tanto el urbanismo a escala urbana como aquel otro, concebido a gran escala, rompieron con lo que había sido el modelo urbano de una primera «Ilustración».

$* * * * *$

8. SAmbricio, Carlos. «Proyectos espaciales en la América hispana en el último tercio del siglo XVIII: Economía política y ordenación del territorio». Urban, 2014, 7; [En línea]. Madrid: ETS Arquitectura Madrid. http://oa.upm.es/36103/1/Sambricio_Urban_opt.pdf. Consultado agosto 2015.

9. CADAlso, José. Noches Lúgubres imitando el estilo de las que escribió en ingles el Doctor Young. Madrid, 1789-1790. Existe copia manuscrita, fechada en 1775, en el Museo Británico; sobre esta, ver Glendinning, Nigel. Vida y obra de Cadalso. Madrid: Gredos, 1962; CAPMANY, Antonio de. Historia del comercio y las artes de la antigua Barcelona. Barcelona: Sancha, 1779-92, 4 tomos. 
Aceptemos el supuesto de que la modernidad comienza cuando aparece la complejidad. De ser así, la modernidad en materia de urbanismo comenzó no con la reflexión de Cerdá sobre el Ensanche de poblaciones, sino al cuestionarse -en los años finales del XVIII- la estructura urbana heredada de la historia, proponiéndose alternativas tanto a los cascos existentes como trazando nuevas poblaciones acordes al programa de necesidades asignado a la población. La ciudad proyectada por Cerdá en 1859 era, como en su día señaló Manuel de Solá Morales, la negación dialéctica de la existente. La brillante afirmación llevaba a reflexionar sobre el hecho de que una línea (la marcada por el límite de la ciudad, fuera este murallas o paseos) fuera capaz de delimitar dos modelos urbanos: uno -intramuros- ligado al pasado y otro -el «ensanche»- concebido como alternativa a la historia ${ }^{10}$. Conocemos qué fueron los ensanches decimonónicos, pero poco sabemos de cómo la ciudad ilustrada cambió su imagen formal al tiempo que trastocaba su modo de gestión, configurando a la postre lo que denominamos "la ciudad liberal».

«... Titis, monas, cacatúas, loros en casi todas las ventanas; una calle muy larga, muy ancha; una puerta soberbia, una infinidad de torres, de campanarios; casas de cuatro, cinco, seis, siete y ocho pisos, muy hermosos balcones; la Casa de Correos, la Aduana, la Puerta del Sol; la Plaza Mayor, el ruido perpetuo de las campanas hace la entrada de Madrid verdaderamente alegre, verdaderamente imponente». En torno a la mitad del siglo XVIII, el marqués de Langle -José María Jerónimo Fleuriot- describía, en su Viaje de Fígaro a España, la realidad de un Madrid donde había edificios de hasta ocho plantas, realidad bien distinta a una urbe compuesta en su mayoría - como dibujara Teixeira- por "casas a la malicia». Hasta comienzos de la década de los '70 la práctica urbana se identificó con reformas parciales, llevando a término obras de embellecimiento, alumbrado, alcantarillado e iluminación y basta en este sentido repasar la Colección Mata Linares (reunión de cédulas, reales órdenes y ordenanzas urbanas ${ }^{11}$ para entender cómo tales

10. Frente a quienes han insinuado que también hubo complejidad en el urbanismo premoderno, convendría recordar cuánto la idea propuesta por Robert Venturi en su Complejidad y contradicción en la arquitectura permitía comprender cómo fue, en los momentos de la Ilustración, cuando frente a problemas específicos hubo "disparidad de soluciones" no solo en lo formal sino, y sobre todo, en la valoración en el enfoque. Si durante el Renacimiento la reflexión sobre cómo trazar una nueva ciudad tuvo distintas soluciones formales (pero todas ellas coherentes con supuestos comúnmente aceptados) y durante el XVII la solución urbana de tridente se aplicó tanto en la Roma de Sixto V como en Versalles o en Aranjuez, independientemente del hecho de que los problemas que caracterizaron cada uno de los tres proyectos citados fuera de naturaleza distinta, la complejidad en arquitectura aparece cuando el trazado de lazaretos, ciudades industriales, ciudades-arsenales o núcleos de colonización se trazaron desde programas de necesidades específicos, supeditando en consecuencia los trazados formales al programa de necesidades.

Sobre los ensanches del XIX, ver SOlÀ-Morales I RuBió, Manuel de. "La forma urbana de orden abierto. Urbanismo moderno de bloques aislados". Quaderns d'arquitectes. Ciutat funcional i morfología urbana. Barcelona: Universidad Politécnica de Cataluña, 1994.

11. Sobre el texto de Fleuriot ver GarCía MERCADAL, José. Viajes de Extranjeros por España y Portugal. Madrid: Aguilar, 1962, III, pp. 1317-1318. Contreras, Remedios y CorTÉs, Carmen. Catálogo 
intervenciones fueron comunes en las principales ciudades españolas de ambos continentes. Se actuó en el límite de las poblaciones, trazándose paseos arbolados y alamedas que transformaban el límite de la población al tiempo que resolvían la embocadura de los caminos en su encuentro con la ciudad. Se singularizaron los nuevos edificios de la administración, trazándolos con cuatro fachadas a la calle y no, como hasta entonces sucediera, disponiéndoles entre medianeras. Pero en la España de Carlos III la razón del cambio se debió a un doble hecho político: por una parte, el denominado "Motín de Esquilache»; luego, el momento de bonanza económica vivido hasta la crisis de comienzos del XIX.

En 1765 la Enciclopedia señalaba cómo una ciudad era... "la reunión de varias casas dispuestas en calles y cerradas por un recinto común, que ordinariamente eran muros o fosos». Entendida como espacio limitado por murallas capaz de albergar barrios, calles, plazas públicas y otros edificios, el autor del artículo se preocupaba -definiendo la ciudad desde lo existente- en detallar y analizar cada una de las partes que la configuraban. Solo un año más tarde los disturbios que viviera Madrid suscitaron en el monarca (como refleja su correspondencia con Tanucci) un fuerte rechazo hacia la ciudad, optando a partir de ese momento por residir en la misma solo cuarenta días al año: y buscando incrementar el control sobre la ciudad, se dispuso dividir administrativamente la ciudad en "cuarteles» buscando -como se hizo- que cada uno tuviera similar número de habitantes. El plano que detalla cuáles fueron los nuevos cuarteles explicita cómo, hasta el momento, la población se había concentrado en las inmediaciones del Palacio de manera tal que cabría establecer un eje norte-sur (configurado por las calles de Hortaleza, Montera, Sol, Carretas y Toledo) que dividiría la ciudad en dos, con fuerte densidad habitacional en la primera (la comprendida entre el río y el citado eje) y escasa población (como testimonia la Planimetría) en la comprendida entre el citado eje y los $\operatorname{Prados}^{12}$. Se daba el caso de que en la zona próxima a los Prados algunas manzanas llegaban a tener una superficie casi veinte veces mayor que otras situadas inmediatas a Palacio; y si las primeras estaban ocupadas por solo tres familias, las situadas en el viejo casco urbano lo estaban por casi sesenta. El momento de bonanza económica que comenzaba a vivir el país se reflejó en un incremento poblacional de la capital que ceñida por la Cerca- creció verticalmente. En los barrios ocupados por el viejo caserío la altura máxima -no olvidemos las consecuencias que tuvieron las disposiciones de Felipe II- no superaba las dos plantas, por lo que la actividad edilicia consistió

de la Colección Mata Linares. Madrid: Real Academia de la Historia, 5 vols., 1970. Sobre ordenanzas municipales ver tanto EzQuiaga Domínguez, José María. Normativa y forma de la ciudad: la regulación de los tipos edificatorios de la ordenanza de Madrid. Tesis ETS Arquitectura (UPM, 1990, ver http:// oa.upm.es/12743/1.pdf. Consultada 16 agosto 2015) como SABATÉ Bel, Joaquim. "Normas y prácticas urbanísticas». En ANGuita CANTERO, Ricardo y HueTz DE LEMPS, Xavier. Ciudades españolas e hispanoamericanas (siglos XVIII-XXI). Madrid: Casa de Velázquez, 2010, pp. 19-36.

12. Sobre la Planimetría de Madrid ver MArín PERellón, Francisco. "La Planimetría General de Madrid y la Regalía de Aposentos». En La Planimetría General de Madrid. Madrid, 1989, pp. 81-111. 
en tirar y levantar substituyéndose las antiguas "casas a la malicia" por edificios de cinco, seis y hasta siete plantas ${ }^{13}$.

Si entre 1780 y 1820 el clasicismo, como proyecto unificador de la arquitectura, fue cuestionado por quienes reclamaban el estudio de las características locales, también las ciudades se trastocaron. Frente a la construcción de paseos o alamedas trazados en los primeros momentos de la segunda mitad del siglo, en los años finales del mismo se propuso dotar a las ciudades de un espacio colectivo" capaz de valorarse como "nuevas ágoras» (lugares de encuentros ciudadanos), trazándose imágenes que se identificaron con el ideal de «la nueva Roma». Si en el XVII la Plaza Mayor había sido espacio de representación, la propuesta formulada con Fernando VI sobre la conveniencia de adecentar los límites de la ciudad, resolviendo la embocadura de los caminos extramuros con las vías urbanas, en los años de Carlos III el uso de aquellos paseos (básicamente, los tres Prados situados entre el Buen Retiro y la ciudad) cambiaba trastocando la función representativa en espacio de encuentro, paseo y disfrute de la población. El paso siguiente lo daría Juan de Villanueva cuando -tras el incendio ocurrido en la madrileña Plaza Mayor en 1790tomó la reconstrucción de lo destruido como pretexto, buscando no restaurar lo dañado cuanto -como hiciera Wren en Londres, tras el incendio de 1666- modificar la imagen de la Plaza -abierta, hasta el momento, a distintas bocacalles-, proponiendo en su lugar no solo un modelo de plaza cerrada sino actuando sobre el entorno, redefiniendo -como arquitecto municipal- las alturas de las edificaciones inmediatas a la Casa de la Panadería, unificando las fachadas de la zona merced a unas rígidas Ordenanzas, buscando con ello no tanto trastocar la trama urbana cuanto definir una nueva imagen del centro histórico de la ciudad. De este modo, la Instrucción dispuesta por Orden del Consejo sobre el Incendio imponía -desde la calle de Postas a la plaza de Santa Cruz, plaza de la provincia y calle Imperial- una normativa ${ }^{14}$ fijando además la citada Instrucción la presencia de soportales porticados, buscando que el citado entorno de la Plaza presentara -desde la preocupación por dar unidad al conjunto- una única fachada.

Frente a la arquitectura como hecho singular ahora era «la calle» (recordemos el anterior comentario de Fleuriot) el elemento generador de la nueva imagen urbana. Al estar Villanueva obligado -como Maestro mayor del Ayuntamiento- a mantener la trama y no poder sustituir los edificios existentes en 1795 impulsó la citada Instrucción mediante la cual se fijaba cómo... "organizar pilastras y capiteles de buena cantería, con el frente de dos pies y medio y tres de tizolas

13. Sambricio, Carlos. "Vivienda y crecimiento urbano en el Madrid de Carlos III». En Catálogo de la Exposición Carlos III, Alcalde de Madrid. Madrid: Ayuntamiento de Madrid, 1989 pp. 381-448.

14. La Instrucción dispuesta de Orden del Consejo y aprobada por S.M. a las Reglas que deben observar para la reconstrucción de las casas arruinadas de la Plaza mayor, con motivo del incendio ocurrido la noche del día 16 de agosto de 1790 se encuentra en ASA 1-82-2. Ver CHUECA, Fernando. Juan de Villanueva. Madrid, 1949, p. 274 y SAMBricio, Carlos. "Una propuesta urbana para la Calle Mayor». Arquitectura, 1996, 307, pp. 29-38. 
intermedias; y en el ángulo, de tres pies y medio o cuatro por frente de cada lado» ${ }^{15}$ al tiempo que obligó al uso de determinados materiales, normalizando así mismo los elementos decorativos.

Su pretensión fue fijar una única fachada entre Platería y San Miguel, idéntica tanto a la que debía caracterizar el tramo entre Imperial hasta San Cristóbal o desde Postas hasta la Puerta de Guadalajara. Recurrió -como elemento unificador- bien al uso de pilastras que aparecen tanto en la calle Toledo, bien a otras (menores en tamaño, pero iguales en proporciones y diseño) dispuestas en la plaza de la Provincia, San Jacinto y Santa Cruz. El nuevo ámbito debía caracterizarse por la regularidad y ritmo en los frentes de fachada y, convencido de cuánto la imagen urbana de la nueva zona debía caracterizarse por su arquitectura y no por la actividad comercial del entorno, propuso dignificar la trama mediante el derribo selectivo de ciertas manzanas, potenciando ciertas fachadas como lo prueba el derribo que quiso llevar a efecto en la esquina de la calle Mayor con Chamberga y plaza de San Miguel. Configurar una imagen unitaria de barrio fue el antecedente de la propuesta que, en 1813, planteara Pedro Manuel de Ugartemendía para reconstruir San Sebastián, proyecto que caracterizó en su alegato ante la Academia de San Fernando al señalar cómo... "una ciudad se construye una vez y para miles de años».

No entendamos lo anterior como anécdota erudita: haciendo abstracción, convendría entender la propuesta de Villanueva en sintonía con los proyectos concebidos en estos años por Percier y Fontaine para la parisina rue Rivoli, con la imagen definida para Karlsruhe, con el milanés Foro Bonaparte proyectado por Antolini o la ya citada idea presentada por Ugartemendía para San Sebastián. Común a todos ellos fue tanto la uniformidad de fachadas como la voluntad por redefinir los espacios públicos de manera tal que la propuesta de Villanueva para el entorno de la Plaza Mayor ayuda a valorar un doble hecho. Por una parte, que intervenciones de este tipo (proponer el derribo de manzanas para «esponjar» un barrio) existían en España antes de la llegada de José Bonaparte. Luego, que el debate sobre que debía ser "una calle» fue tema propuesto en la Academia de San Fernando como ejercicio a quienes pretendían obtener el título de «académicos de mérito", evidenciando así cuánto el debate sobre las ordenanzas municipales -lejos de ser tema estrictamente administrativo- se había convertido en cuestión básica para quienes buscaban definir la nueva imagen de ciudad.

En 1792 Juan de Villanueva propuso -como director general de la Academia de San Fernando- reformar el plan de estudios de la misma. Momento clave en la Academia, como estudió Enrique García Melero, Villanueva presentaba tal idea

15. El expediente para modificar las casas de Platerías y Milaneses, 11, 12 y 13 (ASA 1-171-21, manzana 415, fechado en 1795) detalla cómo en el inicio con la Puerta de Guadalajara se presenta la salida a Platerías, razón por la que se señala la necesidad de... «organizar pilastras y capiteles de buena cantería, con el frente de dos pies y medio y tres de tizolas intermedias. Y en el ángulo de tres pies y medio o cuatro por frente de cada lado". 
apoyándose en un hecho generacional: el acceso a la docencia de un grupo de jóvenes formados por quienes basaban su reflexión no en el estudio de la antigüedad y sí, por el contrario, en los debates abiertos por la Academia de Paris sobre los espacios urbanos con vocación cultural. Ignorando ahora el estudio de las ruinas, en los proyectos presentados por los alumnos de San Fernando en los últimos años del siglo a los Premios se advierten tanto referencias a las barrières parisinas construidas poco antes por Ledoux como a los teatros trazados por Boullée. Que en 1792 Silvestre Pérez pidiera licencia a la Academia para marchar a Paris o que Juan Gómez obtuviera en Roma el Primer Premio en el concurso Clementino de 1795 presentando un tema que él mismo había esbozado en sus años de formación parisina ${ }^{16}$ debe comprenderse como reflejo del interés que Haan, Cellés, Marichalar... profesaron por la arquitectura francesa en los momentos de la Revolución. Si en torno a 1750 los arquitectos viajaron a Roma para allí dibujar las ruinas y entender las "reglas" del clasicismo, en los primeros años del siglo -y como señalara Goethe- se buscaba ver la antigüedad con los ojos del alma.

Del estudio de las antigüedades al mito de la Nueva Roma ${ }^{17}$. Si en torno a 1770 las Nuevas Poblaciones de Sierra Morena o Andalucía se denominaron (en homenaje a la Monarquía) "La Carolina», "La Fernandina» O "La Isabela», a finales del siglo las nuevas poblaciones ahora edificadas se llamaron «Nueva Atenas» O «Nueva Carteya». Por lo mismo, si en torno a 1780 en el proyecto de Marina para Tarragona (el concebido para Alicante o el trazado para puerto de Santander) el espacio abierto dejaba de ser Plaza Mayor en torno a la cual se disponían los edificios del Poder, situándose ahora en la misma los característicos de la nueva actividad comercial (al ser esta marítima, allí se ubicaron atarazanas, almacenes o pescaderías), en los trazados en los primeros años del XIX se buscó sustituir los mismos por "ágoras» cuya función no fuera ya ni representativa ni comercial y sí, por el contrario, espacio colectivo, entendido como lugar de reunión ${ }^{18}$. Por ello, para mejor comprender cómo se valoraba y entendía la ciudad en los finales del XVIII y primeros años del XIX convendría tener presentes las «memorias» presentadas por quienes, titulados ya arquitectos en la Academia de San Fernando, pretendían obtener el grado de académicos de mérito, para lo que debían presentar por escrito un texto, desarro-

16. SAmbricio, Carlos. «Sotto tutti i climi l'uomo è capace di tutto. Gli architetti spagnoli a Roma tra il 1747 e il 1798". En Contro il Barocco Apprendistato a Roma e pratica dell' architettura civile in Italia 1780-1820. Roma: Academia Nazionale di San Luca, 2007, pp. 37-50.

17. Donato, Maria Pia. "Lo specchio di un progetto politico. L'antichità nella Repubblica giacobina romana", "Dimensioni e problemi della ricerca storica», 1994, pp. 82-119. Igualmente, ver PARKER, Harold Talbot. The Cult of Antiquity and the French Revolutionaries. Chicago, 1937.

18. Frente al tópico de que las nuevas poblaciones trazadas en el XVIII fueron ciudades de colonización, convendría estudiar nuevas poblaciones industriales o militares como la Nueva población de Almadén, trazada tras el descubrimiento de una mina de antimonio; la Colonia Fernandina, concebida en Sevilla; el bilbaíno Puerto de la Paz; la Nueva población de Bonanza, en Cádiz; la Ciudad militar para 100.000 hombres, en Alcalá de Henares; la Colonia cervantina, en Badajoz, o la propuesta de Ugartemendía para San Sebastián. 
llando el tema propuesto como la realidad del país. Si en 1795 el trazado de la nueva calle principal de La Coruña ${ }^{19}$ abrió un importante debate, al poco -en 1809, y en plena Guerra napoleónica- Suchet dictaba normas urbanísticas (ii!!) imponiendo a los alcaldes de los 13 partidos de Zaragoza las pautas que debían cumplir ${ }^{20}$. Y que tales indicaciones calaron entre los profesionales de la arquitectura lo prueba que la Academia, finalizada la Guerra, adecuara estas a la cultura urbanística proponiendo de manera reiterada, a lo largo de casi quince años, dos cuestiones como temas de examen: Descripción de las diferentes formas de calles que se conocen en las grandes poblaciones, las ventajas e inconvenientes que presentan cada una y, en segundo lugar, Cómo configurar una ciudad de seis mil habitantes.

El primer tema -definición de diferentes calles en grandes poblaciones- reflejaba la voluntad de abandonar la ciudad histórica. Interviniendo en la misma, trastocaba su trama y proponiendo tanto un nuevo viario como una primera zonificación por usos (próxima de lo que poco más tarde se proponga en Madrid al trazarse la calle del Arenal como eje comercial). El segundo tema propuesto -configurar una ciudad de seis mil habitantes- encajaba -al proponer la actuación a una escala menor- con preocupaciones anteriores. Sobre el primero importa recordar que, en 1812, la Constitución de Cádiz había sacralizado (en su artículo 173) el concepto "propiedad privada" al señalar cómo... «no puede el rey tomar una propiedad de cualquier particular ni turbarle en la posesión, uso y aprovechamiento de ella... y si en algún caso fuera necesario para objeto de conocido utilidad, no lo podrá hacer sin que al mismo sea indemnizado». Cambiaba, en consecuencia, la gestión de la ciudad quedando claro que... «no son los arquitectos los que edifican las ciudades: el legislador fabricó el modelo en el que los hombres de negocios hicieron discurrir sus materiales; la ciudad se formó, en consecuencia, a modo de producto industrial y es reflejo de ordenanzas, plano regulador y sociedad civil ${ }^{21}$. Pese a ello, solo un año más tarde Pedro Manuel de Ugartemendía presentaba a la Academia su proyecto de reconstrucción para un San Sebastián destruido durante la guerra, reclamando el apoyo de la Corporación ante la oposición de los propietarios del suelo que anteponían sus intereses (al entender que el nuevo trazado era contrario a los mismos), argumentando el arquitecto (y reitero) cómo... «una ciudad se construye de una vez y para miles de años». Si el proyecto del arquitecto reflejaba un saber hacer más que notable, la reacción de los propietarios evidenciaba una nueva conciencia políticoeconómica, al cuestionar una hasta entonces indiscutida atribución de la Corona: el derecho de construir ciudades. Una nueva clase ponía en cuestión el ancestral

19. Expediente formado en virtud de RO y representación de los procuradores, Sindico General $y$ diputados del común de la ciudad de La Coruña, sobre los perjuicios que se seguirán a aquel publico de la nueba delineación de la calle principal, que cita haverse mandado hacer por el Gobernador de aquella Plaza. AHN, Consejos, 1469 (ant.leg.706), Libro 2685, n. ${ }^{\circ} 2$.

20. Arreglo que deberán observary cumplir los corregidores y alcaldes mayores de los 13 partidos de la provincia de Zaragoza... AHN, Estado, leg. 3116, 6 julio 1809.

21. SCHUMACHER, Ernst Friedrich. Lo pequeño es hermoso. Barcelona: Tursen/Blume, 1983, 
privilegio al tiempo que reivindicaba su capacidad para urbanizar entendiendo que la propiedad del suelo era un derecho inalienable. Contrarios al trazado de Ugartemendía por razones por completo ajenas a la arquitectura -pese a carecer de modelo formal alternativo- cederían al arquitecto la redacción de las ordenanzas municipales, si bien impondrían un modo de gestión, consiguiendo el control de las obras de infraestructura (alcantarillado, embellecimiento, alumbrado, alineación de calles...) por cuanto no cuestionaban el sacrosanto derecho a la propiedad.

Si el final de la guerra supuso el paso de la Nueva Roma a una inicial ciudad liberal, el urbanismo afrontó por lo mismo un singular paso en la ordenación espacial del territorio. Tras la "francesada" Gobierno y Academia ignoraron tanto las propuestas presentadas en las Cortes de Cádiz sobre una posible división provincial del país (de León del Arroyal a Bauzá o Larramendi, pasando por la difusión que Jovellanos hiciera de los textos de Mably) como las planteadas por el Gobierno de José I o las propiciadas por los generales napoleónicos en Tarragona, Santander o Valencia. Durante los años de guerra la intervención en ciudades existentes había sido (junto al urbanismo a gran escala) tema de singular trascendencia como lo evidencia que, tras la misma, la Academia demostró compartir los criterios de quienes habían pasado de ser "súbditos» a ser "ciudadanos" (esto es, con quienes reclamaban ahora el control sobre las intervenciones urbanas) al incluir -entre los temas propuestos a quienes buscaban ser nombrados académicos- dos relativos a cuestiones urbanas. La mayoría de las "memorias" presentadas por quienes desarrollaron el tema Descripción de las diferentes formas de calles se ajustaron al viejo saber, evidenciando no solo un total desconocimiento del tema sino ignorando los ejemplos europeos, limitándose a citar (como ejemplo de saber-hacer urbano) a Bails o Patte, cuando no a Francesco di Giorgio o Alberti.

Durante casi veinte años las «memorias» presentadas avalaron la pretensión del legislador (las obras de infraestructura eran las únicas intervenciones precisas) por lo que disparatar sobre Tiro, Nínive, Persépolis o -tras reclamar la cuadricula y la trama ortogonal, tomar a Turín, Odesa o Lisboa como ejemplo- ${ }^{22}$ carecía

22. La casi totalidad de las memorias presentadas sobre el tema muestran una sorprendente ignorancia: Salustiano Ardanaz (Disertación describiendo las diferentes formas que se conocen de calles en las grandes poblaciones. Sevilla, 1829, ASF 3-310-11) efectuaba un somero recorrido por la arquitectura antigua, proponiendo el trazado de Babilonia como referencia de trama ortogonal. Juan Daura (Describir las diferentes formas que se conocen de calles en las grandes poblaciones. Madrid, 1831, ASF 3-311-1) proponía un texto más literario y técnico, sin plantear una sola referencia concreta. Andrés Bazán Díez (Descripción de las diferentes formas de calles que se conocen en las grandes poblaciones... Madrid, 1832, ASF 3-308-36) argumentaba con citas idénticas a las que había planteado Ardanaz, lo que lleva a pensar sobre cuánto disparate era la pauta común en esta materia entre los alumnos de San Fernando. Proponía el estudio de las grandes capitales a través de la historia. Ver, así mismo, Jose Fernández Sierra (Disertación sobre las diferentes formas que se conocen de calles. Madrid, 1832, ASF 3-308-30) o Miguel Gálvez (Disertación sobre la descripción de las diferentes formas que se conocen de calles. Madrid, 1842, ASF 3-312-21). Sin duda la única memoria de interés fue la presentada por Juan 
de importancia para la Academia, máxime cuando la competencia acerca de la construcción de ciudades había ya sido asumida por los ingenieros de caminos. El único gesto de modernidad se produjo en 1834 cuando el barcelonés Juan Soler presentó una "Memoria» donde evidenciaba no solo conocer la realidad urbana de Londres y Paris de la época (detallando las características de las principales calles de ambas ciudades), sino que -tras criticar la situación urbanística de Barcelonaprecisó haber visto en Paris... «un nuevo tipo de calle comercial dispuesta en el interior de las manzanas, calle cubierta y con profusión de comercios». Aquella definición del "pasaje» es la primera referencia que desde la arquitectura española se hace sobre el nuevo urbanismo decimonónico. Y, dando un paso más allá, no solo enfatizaría la importancia de la idónea elección del terreno, sino que reclama la necesidad de levantar plano del proyecto, consciente de cómo la ciudad vivirá a corto plazo... «importantes cambios, cuando la industria llame los trabajadores del campo ofreciéndoles un nuevo modo de vida» ${ }^{23}$. Pero hubo, en materia de urbanismo, otra reflexión de naturaleza inédita hasta el momento: la valoración del territorio y la voluntad por sustituir la antigua división provincial por otra concebida desde la voluntad por crear espacios económicos.

$* * * * *$

Soler (Disertación sobre las varias formas que se conocen de calles en grandes poblaciones. Barcelona, 1834, ASF 3-313-19), quien demostró conocer la realidad urbana llevada a término en la Europa de aquellos años. Entiendo que este texto es la charnela que liga lo que fue el urbanismo de la Ilustración y las propuestas concebidas para ciudades que comenzaban su industrialización.

Sobre los "pasajes» en el XIX ver SAMBRicio, Carlos. "Arcades in Early Nineteenth-Century. Madrid». Cittá EStoria, gennaio-giugno 2010, V, 1, pp. 159-182.

23. Sobre el tema propuesto por San Fernando, "Formación de una ciudad capaz de seis mil vecinos", conocemos tanto el presentado por Melchor Cano como la memoria de José Joaquín Trocóniz y convendría efectuar al respecto una doble reflexión: en primer lugar, el tema se ajusta más a lo que fueron las últimas nuevas poblaciones de la ilustración que no a un texto premonitorio sobre cuáles deberían ser los núcleos industriales. Trocóniz presentó su memoria en 1814 (Cuáles deben ser las miras de un arquitecto para la formación de una ciudad capaz de seis mil habitantes. Madrid, 1814, ASF 3-311-4 y 3-310-40) y Melchor Cano en 1822 (Cuáles deben ser las miras de un arquitecto en la formación de una ciudad capaz de seis mil vecinos. Madrid, 1822, ASF 3-310-18). De ambas di en su día referencia en mi trabajo Territorio y ciudad en la España de la ilustración (ibid. nota 17); Trocóniz citaba solo los textos de Vitruvio y Alberti, desconociendo cuanto había sucedido y cuanto se había escrito en materia urbanística en la Europa de principios del XIX, centrando su argumentación en la necesidad de clasificar los edificios en tres categorías: en una primera agrupaba los ligados tanto al poder político como al religioso; en un segundo bloque englobaba dotaciones y equipamientos, y entendía el tercero configurado por las viviendas de los particulares.

La Memoria de Melchor Cano ha sido dada a conocer por ANTIGÜEDAD DEL CASTILLO-OlivarEs, Dolores («El arquitecto Melchor Cano y la teoría de la ciudad». Espacio, Tiempo y Forma, 1990, Serie VII, Historia del Arte, 3, pp. 417-439), reproduciendo párrafos de la misma y enfatizando la idea de que la "forma de la ciudad" debía ajustarse a una planta hexagonal, disponiéndose en cada uno de los lados una puerta de entrada, así como enfatizando que la población debía quedar rodeada mediante una amplia alameda arbolada, de tres calles, que sirviera para disponer -fuera por tanto de la poblacióntanto arrabales como equipamientos. 
Paralelamente a las intervenciones en los cascos urbanos, por vez primera apareció una reflexión sobre el urbanismo a gran escala o, lo que es lo mismo, sobre la escala territorial centrada en razones económicas. Buscando incrementar la riqueza de la Nación, desde opiniones que ya nada tenían que ver con el arbitrismo de comienzos del XVIII (del "proyectismo como género») ${ }^{24}$, desde dos puntos de vista complementarios se plantearon proyectos que tendrían como consecuencia modificar una división territorial ligada al pasado. Por una parte, desde la voluntad por fomentar la velocidad de tráfico de la moneda se crearon nuevos mercados o, lo que es lo mismo, se llevó a término una política de repoblación de zonas despobladas; al tiempo, buscando facilitar el transporte de mercancías, se afrontó la construcción de una red de caminos y canales. Para llevar a término ambos proyectos se imponía el conocimiento fidedigno tanto de la geografía como de la realidad económica del país y, buscando ambos, en 1785 Floridablanca imponía llevar a término un "Interrogatorio» que posibilitara conocer el número de núcleos de población, extensión, población y riqueza de su entorno territorial para, con dichos datos, llevar a término un división administrativa del país. Cuatro años más tarde se presentaba el Nomenclátor o División de Floridablanca, donde la España metropolitana quedaba configurada en 34 provincias y 31 intendencias $^{25}$, buscando con ello dar satisfacción a quienes habían reclamado la necesidad de definir una nueva organización territorial.

A finales del siglo XVIII León del Arroyal -en la Carta IV de las que dirigiera al conde de Lerena- había cuestionado la organización territorial existente al destacar cómo... «el mapa general de la península representa cosas ridículas de unas provincias encajadas en ángulos desregularísimos en todas partes, capitales situadas en las extremidades de los partidos, intendencias extensísimos y intendencias muy pequeños, obispados de cuatro leguas y obispados de setenta, tribunales cuya jurisdicción apenas se extiende fuera los muros de una ciudad y tribunales que abrazan dos o tres reinos». Denunciaba tanto la desproporción y heterogeneidad de las provincias como la coexistencia de múltiples regímenes jurisdiccionales -solapamiento de competencias- identificando el Nomenclátor hasta 30 modalidades administrativas diferentes. "Las provincias, en el estado en que hoy las tenemos, no las formó la presión de la economía sino las casualidades de la guerra. Las capitales se eligieron en las ciudades sin considerar las ventajas de su situación y los pueblos se les agregaron a proporción de las conquistas sin tener presente

24. MuÑoz PÉREZ, José. "Los proyectos sobre España e Indias en el siglo XVIII: el proyectismo como género». Revista de Estudios Políticos, mayo-junio 1955, vol. LIV, n. ${ }^{\circ}$ 81, pp. 169-195.

25. España dividida en provincias e intendencias, y subdividida en partidos, corregimientos, alcaldias mayores, gobiernos políticos y militares, así realengos como de órdenes, abadengo y señorío. Obra formada por las relaciones originales de los respectivos intendentes del reyno, a quienes se pidieron de orden de S.M. por el... Conde de Floridablanca... en 22 de marzo de 1785. Con un nomenclator o diccionario... de las ciudades, villas, lugares, aldeas... con expresión de la provincia, partido y término a que pertenecen. Madrid, Imprenta Real, 1789. 
otro respecto de la comodidad de las defensas». A las críticas de León del Arroyal pronto se sumaron los comentarios que Isidoro de Antillón (luego activo diputado en las Cortes de Cádiz) hiciera sobre aquel mapa de intendencias, calificándolo de... «irracional, anacrónico, desproporcionado, irregular o monstruoso» ${ }^{26}$.

Si la reordenación del territorio había sido tema debatido por los reformistas políticos (recordemos la utopía Sinapia) nunca, hasta el momento, la Academia de San Fernando había afrontado cómo diseñar una ciudad ni, tampoco, cómo definir un nuevo espacio económico. Conocer el territorio se había convertido en especial preocupación de una sociedad que, en breve plazo, evidenció su interés por pasar de lo cuantitativo a valorar lo que se estudiaba. Así, el Viaje de Ponz (enumerativo y descriptivo) dio paso, pocos años más tarde, al redactado por Bosarte, interpretativo y valorativo; por lo mismo, el Nomenclátor de Floridablanca propició el Diccionario promovido por Campomanes. Frente a aquellos, los «viajes» de comienzos del XIX fueron por completo extraños (por los temas tratados) a las "guías de forasteros" publicadas durante la segunda mitad del siglo XVIII, de igual manera que las descripciones que hiciera Laborde nada tuvieron en común con los «Itinerarios» militares elaborados solo diez años más tarde. Conocer el territorio implicaba conocer su geografía y la experiencia americana influyó de manera determinante en ingenieros militares como Felipe Bauzá o Félix de Azara quienes, en sus opiniones, coincidirían con las expresadas de un geógrafo como Caldas que, refriéndose a la América hispana, apuntaba... "los conocimientos geográficos son el termómetro con que se mide la ilustración, el comercio, la agricultura y la prosperidad de un pueblo. Su estupidez y su barbarie siempre es proporcional a su ignorancia en este puntom ${ }^{27}$.

Si la preocupación era conocer el comercio y la agricultura, pronto se cuestionó la imagen de una España definida como agregación de reinos históricos.

26. Citado en fecha tan temprana como 1973 por Rubiales, Amparo. La Región: historia y actualidad. Sevilla: Instituto García Oviedo de la Universidad de Sevilla, 1973, pp. 383-388, existe importante bibliografía sobre el tema. Ver ViLaR, María José. "El primer proyecto liberal de división provincial de España. El propuesto por Felipe Bauzá y revisado por Miguel de Lastarría, 1813-1814». Anales de Historia Contemporánea, 20, 2004, pp. 21-63, así como GARRIGÓs PICÓ, Enrique. "Organización territorial al final del Antiguo Régimen». En ARTOla, Miguel (ed.). La economía española del final del Antiguo Régimen. Madrid, 1982, t. IV, pp. 1-105.

Sobre Antillón ver Elementos de la geografía astronómica, natural y política de España y Portugal. Madrid: Fuentenebro, 1808, así como CAPEL, Horacio. «Isidoro de Antillón (1778-1814)». Boletín Informativo. Madrid: Fundación Juan March, enero 1987, 166, pp. 3-18, asi como Fernández Clemente, Eloy. "Isidoro de Antillón: política y economía de un diputado liberal». En Josep Fontana. Historia i projecte social. Reconeiximent a una trajectoria. Barcelona: Crítica, 2004, pp. 999-1022. Así mismo, JAIME LOREN, José María. "Censura a una censura de la Geografía de Isidoro de Antillón, con nuevas noticias sobre el gran geógrafo y liberal turolense». Cuadernos de Ilustracion y Romanticismo, 2004, 12, pp. 79-106. p. 1.

27. Caldas, José de. Semanario del Nuevo Reyno de Granada. Santafé, 1, 3 de enero de 1808, 
Cayetano Soler -ministro de Hacienda con Godoy- ${ }^{28}$ propondría constituir... «a efectos fiscales y buscando potenciar el comercio litoral» seis nuevas provincias (Santander, Asturias, Cádiz, Málaga, Cartagena y Valencia) que, por su ubicación, denominó marítimas y, segregándolas de lo que habían sido antiguos reinos, proponía su división administrativa desde criterios fiscales, argumentando de manera similar a como años antes lo hicieran Diderot y D'Alambert desde la Encyclopédie. La Guerra napoleónica dio pie a que, simultáneamente, se propusieran diferentes propuestas de reordenación del territorio: la primera, enunciada por el Emperador en 1809, anexionaba a Francia -con el argumento de «resarcimiento por gastos de guerra»- el territorio comprendido entre el Ebro y los Pirineos estableciendo -en una Cataluña integrada en la Administración del Imperio- cuatro departamentos a los que aplicaba los criterios de la división prefectural napoleónica. Si bien Cataluña se integró en aquella administración, la anexión no se llevó a efecto debido, entre otras cosas, a que el propio José I, mediante decreto dado en Sevilla en abril de 1810, tras reclamar la integridad territorial de España, proponía la reordenación territorial del país ${ }^{29}$.

Conocemos la situación: tras la victoria francesa de Ocaña y aprovechando las disensiones existentes en la Junta Central (lo que, en la primavera de 1810, supuso el repliegue de los patriotas hacia Cádiz y la casi total ocupación francesa de Andalucía) José Bonaparte creyó que el final de la contienda estaba próximo aprobando en Sevilla un mapa prefectural para España donde el concepto «espacio natural» aparecía ligado al de "patrias locales». Conforme a lo señalado, José Antonio Llorente -en su Reglamento para la Iglesia Española- ${ }^{30}$ recomendaba a José I hacer coincidir la división civil de España con la administrativa, indicando así mismo la conveniencia de que cada capital de provincia dispusiera de un tribunal de apelación, arzobispo, prefecto y comandante. Al tiempo, proponía establecer en cada capital de departamento un tribunal de Primera Instancia, obispo,

28. Escudero, José Antonio. "El Ministerio de Hacienda y la reforma de Soler (1800)». En Homenaje a Ismael Sánchez Bella. Pamplona: Universidad de Navarra, 1992, pp. 231-237.

29. Prontuario de las Leyes y Decretos del Rey Nuestro Señor D. José Napoleón I. Madrid, 1810, t. II, pp. 56 y ss. Sobre José Antonio Llorente y su proyecto de reordenación territorial véase JURETSCHKE, Hans. Los afrancesados en la guerra de la Independencia. Madrid: Rial, 1962; ARTOLA, Miguel. Los afrancesados. Madrid: Alianza Editorial, 1976; LÓPEZ TÁBAR, Juan. Los famosos traidores. Los afrancesados durante la crisis del Antiguo Régimen (1808-1833). Madrid: Biblioteca Nueva, 2001. Un análisis del Decreto puede verse en el clásico trabajo de Melón, Amando. "El mapa prefectural de España (1810)». Estudios Geográficos, 1952, XIII, pp. 5-72 así como en MERCADER RIBA, José. La organización administrativa francesa en España. Zaragoza, 1959 y del mismo autor: José Bonaparte, rey de España (1808-1813). Estructura del Estado español bonapartista. Madrid: CSIC, 1983.

30. LAma Cereceda, Enrique de. J. A. Llorente, un ideal de burguesía. Su vida y su obra hasta el exilio en Francia (1756-1813). Pamplona: Universidad de Navarra, 1991; BurgueÑo RIvERO, Jesús. "Las prefecturas de 1810". Argutorio, 2. ${ }^{\circ}$ Semestre 2012, 29/22; Dufour, Gerard. Juan Antonio Llorente. El factótum del Rey Intruso. Zaragoza: Universidad de Zaragoza, 2014 o FernÁndez SiRvent, Rafael. "Un comisario regio de José I: Francisco Amorós». Historia Constitucional (revista electrónica), 2008, 9. http://hc.rediris.es/09/index.html. 
subprefecto y subcomandante, detallando cómo en cada capital de obispado o departamento era precisa la construcción de un hospital/casa de expósitos/casa de caridad y casa de educación de niños pobres.

No fue aquella la única división propuesta a José I porque -como ha estudiado Rafael Fernández Sirvent- Amorós propondría, en esos mismos momentos, homogeneizar el tamaño y población de las provincias existentes, sugiriendo fragmentar los antiguos reinos y principados en unidades equilibradas. Reclamando fortalecer la cohesión e integración nacional de los nuevos Estados (de los Estados surgidos del Imperio napoleónico) hacía énfasis en cómo la partición espacial debía plantearse buscando la unificación política, sustentando la idea de nación en la reorganización de la malla político-territorial. Su informe suponía definir 38 departamentos, acorde con lo expuesto poco antes en el Estatuto de Bayona donde se señalaba que... «los diputados de las provincias adyacentes de España serán nombrados por estas a razón de un diputado por 300.000 habitantes poco más o menos». Y si tal proyecto nunca fue aprobado, no ignoremos que el mismo sirvió de base (por ejemplo, la existencia de 38 demarcaciones) al mexicano José María de Lanz y Zaldívar en la Memoria que presentara en $1809^{31}$.

La guerra contra el francés, lejos de dividir al país entre partidarios de José y defensores de las Cortes de Cádiz (esto es, entre "patriotas» o «afrancesados») dividió en realidad el país entre quienes reclamaban abandonar el Antiguo Régimen y aquellos otros que, por el contrario, reclamaban una monarquía tradicional. Las ideas expuestas por Llorente, Amorós o Lanz y Zaldívar reflejaban una preocupación común a quienes se interesaban por la economía política, influencia que aparecería en los debates mantenidos en las Cortes de Cádiz al proponerse, en agosto de 1812, una reforma territorial acorde con la nueva realidad nacional. En sesión, Agustín de Argüelles presentó en dichas Cortes su Constitución territorial de España abriendo el debate sobre el "territorio de las Españas» y recogiendo su artículo 10 las opiniones de quienes -ante la realidad plural y compleja del territorio peninsular, contrastes demográficos, fragmentación y diversidad del medio físico, así como de las culturas y tradiciones institucionales...- desaconsejaron (pese a conocerla) la solución geométrica propuesta tanto en Sinapia como por Robert de Hesseln, en 1789, expresando el deseo de establecer... «una división más conveniente del territorio español por una ley constitucional, luego que las circunstancias políticas de la nación lo permitan».

En dichas Cortes chocaron quienes, al defender el absolutismo, reivindicaban mantener los límites de los antiguos reinos históricos con quienes reclamaban el cambio. Si bien la Constitución apuntaba como el país se encontraba dividido en

31. Silván, Leandro. "Datos para una biografía de don José María de Lanz y de Zaldívar». Boletín de la Real Sociedad Bascongada de los Amigos del País. San Sebastián, 1979, XXXV, pp. 57-59. 
19 distritos territoriales de los cuales 14 correspondían a regiones históricas ${ }^{32}$, la solución fue aprobar el ambiguo título II de la Constitución (Del territorio de las Españas, su religión y gobierno, y de los ciudadanos españoles) soslayando así cualquier polémica y posponiendo cualquier acuerdo... «Se hará una división más conveniente del territorio español por una ley constitucional, luego que las circunstancias políticas de la Nación lo permitan». A mediados de 1813, casi ultimada la retirada de las tropas francesas e inmediato el retorno de Fernando VII, la Secretaría de las Cortes expresó a la Regencia haber llegado el momento de poner en práctica el citado artículo de la Constitución, recibiendo Bauzá el encargo de definir la reordenación del territorio metropolitano ${ }^{33}$.

¿Debemos entender lo anteriormente expuesto como proceso único y excepcional? Afirmar tal supondría no solo desconocer el alcance de las discusiones planteadas en la francesa Asamblea Constituyente la noche del 4 de agosto de 1789 (los debates sobre la supresión de privilegios y de antiguas estructuras feudales), sino también la labor que un singular número de estudiosos criollos estaba llevando a término en la América Hispana. En este sentido, ignorar los textos publicados por El Mercurio Peruano sobre las características del reino de Perú o los comentarios de Caldas aparecidos en La Gazeta de la Nueva Granada sería tan equivocado como minimizar las relaciones que los geógrafos españoles mantenían con los criollos, cuando sabemos que Lanz colaboró con Betancourt; que Bauzá trató en 1807 -con su Discurso de Ingreso en la Real Academia de la Historia- sobre El estado de la geografía en la América meridional, o que Humboldt, Caldas y Bauzá mantuvieron una correspondencia cruzada que refleja cuánto el proyecto político de la Independencia conllevaba una propuesta urbana de actuación a gran escala.

La experiencia americana sirvió a Bauzá, ante las Cortes de Cádiz, para buscar equilibrar territorio, población y riqueza. Planteó su propuesta de división sobre la base de tres criterios: mantenimiento de los reinos históricos, división en provincias operativas e introducción de nuevas provincias en los territorios periféricos cuando estas fueran convenientes. Consciente -y así lo explicitó- de las dificultades del encargo recibido del Gobierno (dado que a los desequilibrios territoriales se añadían los demográficos) hizo ver en la Memoria que presentara como, sobre un total de 10.541.221 habitantes (según censo de Floridablanca de 1797), un tercio de la población española se concentraba en cuatro de las 32 provincias. Señalaría, en consecuencia, cómo...

32. SÁNCHEZ Agesta, Luis. Introducción a Agustín de Argüelles. Discurso preliminar a la Constitución de 1812. Madrid: Centro de Estudios Políticos y Constitucionales, 2011.

33. Vilar, María José. "El primer proyecto liberal de división provincial...», op. cit., n. 26. También GAY ARMENTEROS, Juan C. "La estructuración del poder en los comienzos del Estado español contemporáneo». En GAY ARmenteros, Juan C. El mundo contemporáneo. Estudio y reflexiones. Granada, 2002, pp. 89-92. Igualmente García Álvarez, Jacobo. Provincias, regiones y comunidades autónomas. La formación del mapa político de España. Madrid: Secretaría General del Senado, 2002. 
las dos calidades de igualdad en estensión y población entre todas las Provincias en que se había de hacer la Subdivisión son incompatibles, porque una legua quadrada de ciertos distritos o una ciudad sola suele tener más población que muchas leguas de otros. [...] Así es que, aun quando me hubiera decidido a subdividir la periferia de la Península en partes iguales... el resultado sería una monstruosidad efectiva en lugar de aquella perfección aparente, porque dos territorios iguales en estensión daría el uno triple o quádruple población que otro, y los medios y gastos para su gobierno en el uniforme sistema que se ha adoptado deberían ser los mismos ${ }^{34}$.

Reclamó mantener, en su división provincial, tanto las subdivisiones históricas como mantener los límites entre Castilla y sus regiones colindantes, al tiempo que troceaba las antiguas regiones en unidades administrativas (provincias) con la pretensión de que cada una de ellas tuviera en torno a 300.000 habitantes. Al aplicar tal esquema, parceló la España metropolitana en 44 provincias, clasificando estas (en función de su riqueza y población) en tres categorías y fijando cómo en torno a las de primera clase debían disponerse las demás; definió como provincias de segunda categoría aquellas que siendo menos relevantes... "convenía preservar porque siempre se habían manejados solas» (como fuera el caso de Murcia o incluyendo en esta categoría las "marítimas» propuestas por Soler en los comienzos del siglo. Por último, definía como "provincias de tercera categoría" las que entendía que eran subalternas de las de primera clase, entendiéndolas como subprovincias, gobernaciones o distritos dependientes de provincias aquellas otras excesivamente extensas o pobladas ${ }^{35}$.

La diferencia entre su propuesta, la de Soler o la Josefina fue clara: si aquellas respetaban los límites históricos entre los reinos, Bauzá asumía los criterios naturales señalados en el proyecto del Gobierno intruso, si bien sin priorizarlos. A su vez, y frente al proyecto de Soler, no concibió el proyecto en función de la distancia media entre cabeceras de distrito, sino valorando el "peso demográfico" y económico de cada circunscripción. Su plan, presentado en 1814, no fue llevado a la práctica debido a que Fernando VII paralizó todas las iniciativas constitucionales; sin embargo, en 1820 -al iniciarse el Trienio liberal- las Cortes recomendaron la formación de la carta geométrica de España siendo Bauzá nombrado presidente de la Comisión de División del Territorio y de Hacienda, poniendo al día su plan de 1814 y entregando en abril de 1821 al Ministerio de la Gobernación una Memoria sobre la división del territorio.

El fin del Trienio interrumpió (cuando menos, aparentemente) la reflexión sobre la ordenación del territorio: sin embargo, un incipiente protorromanticismo reclamaría de inmediato la reflexión sobre la patria local, buscando en consecuencia diferenciarse de ámbitos geográficos inmediatos. Si en su día Jovellanos

34. Vilar, María José. Op. cit., p. 30, nota 24

35. Estrada SÁnchez, Manuel. Provincias y Diputaciones: La construcción de la Cantabria Contemporánea. Santander: Parlamento de Cantabria y Universidad de Cantabria, 2006, p. 87, n. 38. 
formuló referencias al paisaje, buscando de este modo trasmitir la idea de "sublime», en torno a 1830 la referencia al mismo paisaje se hacía desde criterios distintos, recurriendo a la singularidad del mismo para evidenciar sus diferencias con valoraciones territoriales globalizadoras. Se abrieron, en consecuencia, tres nuevos campos para explicar y evidenciar lo singular de determinadas áreas, para definir quién pertenecía a un espacio y quién, por el contrario, al no cumplir con las citadas características quedaba fuera. Una fue el estudio de la literatura, englobando esta cuanto tenía que ver con la lengua, la cultura popular, las leyendas, tradiciones... Un segundo aspecto diferenciador fue el derecho administrativo, la archivística o la diplomática, por cuanto mediante las mismas era posible determinar el ámbito de determinados privilegios medievales. Por último, los estudios sobre la arquitectura del pasado se plantearon no desde la voluntad por conocer (no, todavía, desde la voluntad de elaborar una "historia de la arquitectura»), sino cuantos argumentos con los que diferenciar áreas de influencia o, lo que es lo mismo, para marcar límites y definir territorios.

\section{BIBLIOGRAFÍA}

ANTigÜEDAD Del Castillo-Olivares, Dolores. «El arquitecto Melchor Cano y la teoría de la ciudad». Espacio, Tiempo y Forma, Serie VII, Historia del Arte, 1990, 3, pp. 417-439.

Arbaiza Blanco-Soler, Silvia. "Los dibujos de arquitectura en la Real Academia de Bellas Artes de San Fernando (Madrid)». arq.urb, primer semestre 2013, 9, pp. 98-113.

Arbaiza Blanco-Soler, Silvia y Heras CaSAS, Carmen. "Inventario de los dibujos Arquitectónicos (de los siglos XVIII y XIX) en el Museo de la Real Academia de Bellas Artes de San Fernando". Academia, (Madrid), entre 2001 y 2007.

ArTola, Miguel. Los afrancesados. Madrid: Alianza Editorial, 1976.

Berbel Rodríguez, José J. Orígenes de la tragedia neoclásica (1737-1754): la Academia del Buen Gusto. Sevilla: Universidad Sevilla, 2003.

BurgueÑo Rivero, Jesús. "Las prefecturas de 1810». ARGUTORIO, 2. ${ }^{\circ}$ Semestre 2012, n. ${ }^{\circ}$ $29 / 22$.

CAPEL, Horacio. «Isidoro de Antillón (1778-1814)». Boletín Informativo Fundación Juan March, enero 1987, 166, pp. 3-18.

CAPMANY, Antonio de. Historia del comercio y las artes de la antigua Barcelona. Barcelona: Sancha, 1779-92, 4 tomos.

CONTRERAS, Remedios y CORTÉs, Carmen. Catálogo de la Colección Mata Linares. Madrid: Real Academia de la Historia, 1970, 5 vols.

Escudero, José Antonio. «El Ministerio de Hacienda y la reforma de Soler (1800)». En Homenaje a Ismael Sánchez Bella. Pamplona: Universidad de Navarra, 1992, pp. 231-237.

Estrada SÁnchez, Manuel. Provincias y Diputaciones: La construcción de la Cantabria Contemporánea. Santander: Parlamento de Cantabria y Universidad de Cantabria, 2006.

EzQuiaga Domínguez, José María. Normativa y forma de la ciudad: la regulación de los tipos edificatorios de la ordenanza de Madrid. Tesis ETS Arquitectura (UPM, 1990 ver http://oa.upm.es/12743/1.pdf). 
ARQUITECTURA, CIUDAD Y TERRITORIO A FINALES DE LA ILUSTRACIÓN

FERnÁNDEZ SiRvent, Rafael. «Un comisario regio de José I: Francisco Amorós». Historia Constitucional, revista electrónica, 2008, 9. http://hc.rediris.es/09/index.html.

García Álvarez, Jacobo. Provincias, regiones y comunidades autónomas. La formación del mapa político de España. Prólogo de Josefina Gómez Mendoza. Madrid: Secretaría General del Senado, 2002.

GARRIGÓS PICÓ, Enrique. «Organización territorial al final del Antiguo Régimen». En ARTOlA, Miguel (ed.). La economía española del final del Antiguo Régimen. Madrid, 1982, t. IV, pp. 1-105.

GAY ARMENTEROS, Juan C. "La estructuración del poder en los comienzos del Estado español contemporáneo». En Gay ARmenteros, Juan C. El mundo contemporáneo. Estudio y reflexiones. Granada, 2002, pp. 89-92.

Glendinning, Nigel. Vida y obra de Cadalso. Madrid: Gredos, 1962.

JURETSCHKE, Hans. Los afrancesados en la guerra de la Independencia. Madrid: Rialp, 1962.

LAMA CERECEDA, Enrique de la. J. A. Llorente, un ideal de burguesía. Su vida y su obra hasta el exilio en Francia (1756-1813). Pamplona: Universidad de Navarra, 1991.

LÁzARO CARRETER, Fernando. "Introducción». En Moratín en su teatro. Barcelona: Labor, 1970, t. 1, p. 232.

LóPez TÁBAR, Juan. Los famosos traidores. Los afrancesados durante la crisis del Antiguo Régimen (1808-1833). Madrid: Nuevos Horizontes, 2001.

Marín Perellón, Francisco. "La Planimetría General de Madrid y la Regalía de Aposentos». En La Planimetría General de Madrid. Madrid, 1989, pp. 81-111.

MERCADER RIBA, José. La organización administrativa francesa en España. Zaragoza, 1959.

MerCader RiBa, José. José Bonaparte, rey de España (1808-1813). Estructura del Estado español bonapartista. Madrid: CSIC, 1983.

Rubiales, Amparo. La Región: historia y actualidad. Sevilla: Instituto García Oviedo de la Universidad de Sevilla, 1973.

SABATÉ Bel, Joaquim. "Normas y prácticas urbanísticas». En ANGUITA CANTERO, Ricardo y HUETZ DE LEMPS, Xavier. (eds.). Ciudades españolas e hispanoamericanas (siglos XVIIIXXI). Madrid: Casa de Velázquez, 2010, pp. 19-36.

SAmBricio, Carlos. "Vivienda y crecimiento urbano en el Madrid de Carlos III». En Catálogo de la Exposición Carlos III, Alcalde de Madrid. Madrid: Ayuntamiento de Madrid, 1989, pp. 381-448.

SAMBRICIO, Carlos. Territorio y Ciudad en la España de la Razón. Madrid: MOPU, 1991.

SAMBricio, Carlos. "Sotto tutti i climi l'uomo è capace di tutto. Gli architetti spagnoli a Roma tra il 1747 e il 1798". En Contro il Barocco Apprendistato a Roma e pratica dell' architettura civile in Italia 1780-1820. Roma: Academia Nazionale di San Luca, 2007, pp. 37-50.

SAmbricio, Carlos. "Arcades in Early Nineteenth-Century. Madrid». Città E Storia, gennaiogiugno 2010, V, 1, pp. 159-182.

SAmbricio, Carlos. "Sinapia: utopía, territorio y ciudad a finales del siglo XVIII". Scripta Nova. Revista Electrónica de Geografía y Ciencias Sociales. [En línea]. Barcelona: Universidad de Barcelona. http://www.ub.es/geocrit/sn/sn-475.htm. 1 de mayo de 2014, vol. XVIII, n. ${ }^{\circ} 475$.

SAmbricio, Carlos. "Proyectos espaciales en la América hispana en el último tercio del siglo XVIII: Economía política y ordenación del territoriom. Urban, 2014, 7; Madrid: Universidad Politécnica. http://oa.upm.es/36103/1/Sambricio_Urban_opt.pdf. 
SÁnCheZ AgeSta, Luis. "Introducción" a ARgüelles, Agustín de. Discurso preliminar a la Constitución de 1812. Madrid: Centro de Estudios Políticos y Constitucionales, 2011. SCHUMACHER, Ernst Friedrich. Lo pequeño es hermoso. Barcelona: Tursen/Blume, 1983.

SEBOLD, Russell P. «Martín Sarmiento y la doctrina neoclásica». Insula, 1977, 366, pp. 1-12. SILVÁn, Leandro. "Datos para una biografía de don José María de Lanz y de Zaldívar». Boletín de la Real Sociedad Bascongada de los Amigos del País, 1979, XXXV, pp. 57-59.

VILAR, María José. «El primer proyecto liberal de división provincial de España. El propuesto por Felipe Bauzá y revisado por Miguel de Lastarría, 1813-1814». Anales de Historia Contemporánea, 2004, 20, pp. 21-63. 